\title{
An Investigation of Practices and Tools that Enabled Technology-Mediated Caring in an Online High School
}

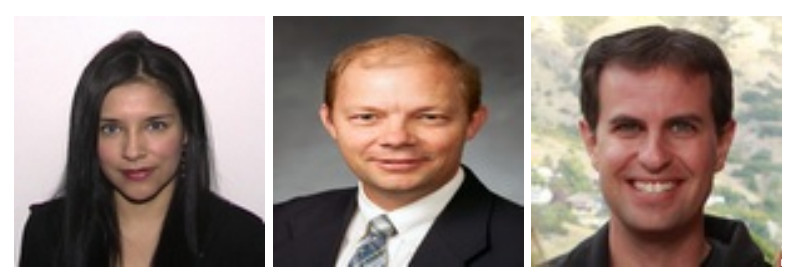

Andrea Velasquez, Charles R Graham, and Richard E West Brigham Young University, USA

\section{Abstract}

The ethic of care has been an important part of the dialogue related to learning in traditional K-12 learning environments particularly because emotional relationships and caring pedagogies have been shown to be particularly important for adolescent learners. However, as online learning has become increasingly popular, there are concerns about the perceived impersonal nature of the online medium, and how this might particularly affect adolescent learners. The purpose of this study was to examine technology choices when experiencing caring interactions in the online schooling context of Mountain Heights Academy (formerly Open High School of Utah). The caring experience of two teacher participants and four of their students was examined through interpretative phenomenological analysis. Results suggest that teacher choices regarding technology use are an integral part of creating caring relationships with students online. The ethics of caring is an essential model in understanding the communication of caring interactions in the online setting.

Keywords: Presence; immediacy; transactional distance; caring pedagogy; technologymediated caring 


\section{Introduction}

Caring has been recognized as an increasingly important concept in the K-12 context (Banks, 2009; Ferreira, Smith, \& Bosworth, 2002; Goldstein, 1998, 2002; Lewis, et al., in press; Tosolt, 2010). Researchers and practitioners have acknowledged that teacher caring is imperative because education is predominantly a moral endeavor (Goodlad, 1984, 1990; Goodlad, Soder, \& Sirotnik, 1990; Noddings, 1984). In experimental studies, caring has been found to increase student motivation and retention (Frymier \& Thompson, 1992; McArthur, 2005), and student affect for the course and for the course instructor (Teven, 2007; Wilson, 2006). Caring has also been found to decrease disruptive behavior (Hasenauer \& Herrmann, 1996; Lindmark, Marshall, Riley, \& Strey, 1996) and increase learning outcomes (Baker, et al., 1997; Lewis, et al., in press; Shann, 1999; Valenzuela, 1999). Furthermore, in studies that have examined the student perspective, factors related to the teacher-student relationship rank of higher importance to students than teacher proficiency (Baker, et al. 1997; Pomeroy, 1999; Wallace, 1996).

Researchers have identified caring as an integral component of child development, motivation, and learning (Baker, Terry, Bridger, \& Winsor, 1997; Wentzel, 1997). Goodenow (1993), for example, found that students experience cognitive changes that lead to an increased need for caring student-teacher relationships. Pomeroy (1999) revealed that in educational settings, adolescents have a need to be cared for in a way that is different from the parent-child caring relationship. In particular, students in this study recognized dialogue as a central factor leading to perceived teacher caring. Notwithstanding, students have reported a perceived decrease in the quality of the teacher-student relationship upon entrance to junior high school (Feldlaufer, Midgley, \&Eccles, 1988; Hirsch \& Rapkin, 1987).

Picciano and Seaman (2007) argued caring is particularly significant in the online context as the demand for online K-12 education has dramatically increased over the last several years. Conceptually, a need to examine caring in the information and communication technologies literature has been acknowledged (Damarin, 1994; Delacruz, 2009; Gleaves \& Walker, 2006). There have been a few empirical studies related to caring in the online context (Bulmer \& Rodd, 2005; Goldstein \& Freedman, 2003), but much of the early distance education research focused on understanding learner-content interaction and issues of autonomy rather than the nature of the learner-instructor relationship. Additionally, more recent literature has characterized learner-instructor interactions as "teacher presence" in the community of inquiry framework (Anderson, Rourke, Archer, \& Garrison, 2001) or as "social presence" in other research (Richardson \& Swan, 2003), and "instructor immediacy" (Arbaugh, 2001) rather than building on the literature of caring. 


\section{Literature Review}

Much of distance learning research has focused on the structure and number of interactions between instructors and students, as well as the ability to use verbal and non-verbal behaviors to reduce the psychological distance between persons in an online setting. While these views are important, we feel that a care-centered approach (Gilligan, 1982; Noddings, 1984) adds a more relational perspective to online interactions that can be useful in understanding how students feel cared for online. In this section, we first begin by reviewing traditional approaches to online learning research, including ideas related to online interactions, particularly the psychological, or transactional, distance between students and instructors. We then review research related to instructor presence and immediacy, before exploring how a care-centered approach to understanding online relationships might help build upon these foundations.

\section{Transactional Distance Theory}

Transactional distance refers to "a psychological and communication space to be crossed, a space of potential misunderstanding between the inputs of instructor and those of the learner" (Moore, 1993, p. 22). The focus of much distance education research built upon Moore's work as scholars considered the "transactions" occurring in learning environments. His theory of transactional distance states that transactional distance decreases when dialogue (communications between student and teacher) increases and course structure (learning objectives, activities, and evaluations) decreases (Moore, 1993). Moore's theory also states that learner autonomy, or the degree to which the learner is self-directed in learning, increases with greater transactional distance (Moore \& Kearsley, 1996). Therefore, teachers have the responsibility of determining the appropriate structure and degree of dialogue in a course based on learners' needs and autonomy (Moore, 1993; Moore \& Kearsley, 1996).

\section{Presence and Immediacy}

Building upon Moore's theories of transactional distance, scholars have studied how social presence and immediacy could describe teacher/student interactions, both online and first in face-to-face contexts (Anderson, et al., 2001; Mehrabian, 1971), particularly with the community of inquiry framework (Garrison, Anderson, \&Archer, 2000).

\section{Presence.}

The community of inquiry (CoI) framework distinguishes between three interdependent elements-social, cognitive, and teaching presence (Garrison, Anderson, \& Archer, 2000). Social presence is related to interpersonal interactions and communication and acknowledges the teacher and student role in creating a social environment. Cognitive presence refers to the dialogue that makes the construction of meaning possible, while teacher presence refers to how an instructor facilitates learning outcomes. Moreover, teacher presence has been divided into three categories: design and organization, 
facilitating discourse, and direct instruction (Anderson, et al., 2001). Research indicates a correlation between teacher presence and student satisfaction and performance (Bangert, 2008; Picciano, 2002; Shea, Pickett, \& Pelz, 2003). These elements of presence have been identified as indicators of the quality of online instruction (Shea, Vickers, \& Hayes, 2010).

\section{Immediacy.}

The element of social presence in the CoI framework includes teacher immediacyverbal and non-verbal behaviors that reduce psychological and physical distance between individuals (Mehrabian, 1971; Andersen, 1979). The online context has largely focused on examining verbally immediate behaviors such as using self-disclosure, using humor, initiating discussion, offering praise, communicating attentiveness, and addressing students in a personal manner (O'Sullivan, Hunt, \& Lippert, 2004). Research indicates that teacher immediacy is more easily afforded through synchronous online interactions (Pelowski, Frissell, Cabral, \&Yu, 2005; Schwier \& Balbar, 2002) and that increased teacher immediacy is related to increased student outcomes and affect (Arbaugh, 2001; Baker, 2004; McAlister, 2001).

\section{A Care-Centered Approach}

While much of distance education research has focused models such as these that emphasize transactions or interactions, research in the area of "caring" has focused on the relational aspect of the teacher-student interaction. Perhaps the foremost theory on caring pedagogies is Noddings' ethic of care theory, which has the potential to help online (and face-to-face) teachers better understand and foster teacher-student relationships.

\section{Noddings' ethic of care theory.}

In the field of philosophy, Noddings (1984) introduced a care-centered approach to ethics that revolutionized the discourse on moral theories and development. Noddings (1984) established that caring requires that the one-caring (the teacher) become engrossed, or receptive to the cared-for with the purpose of understanding him. The one-caring then experiences motivational displacement, or an energy that leads to the execution of actions that improve the cared-for and ensure their progress. The cared-for also contributes to caring through reciprocity-acknowledging the caring acts by reacting to them (Noddings, 1984).

\section{Contributions to online teaching.}

Although research studies on online social presence and immediacy are useful in understanding the process of learning, the caring model has the potential to enrich research on teacher-student interactions because its focus is not on prescriptive behaviors, but understanding and strengthening the teacher-student relationship. In the caring model, caring warrants more than presence, requiring teacher actions that are a product of teachers' receptivity to students' needs. Actions and behaviors are not 
the primary concern, and caring cannot be operationalized into a prescriptive list of actions or behaviors (Noddings, 1984). Rather, engrossment in the student characterized by receptivity-coming to a knowledge of the student-is of primary importance. The engrossment stage provides the necessary rationale and direction for the action that follows. In the ethic of care theory, actions are a byproduct of receptive dialogue and observation that lead a teacher to deeply understand a student. Thus, caring accounts for a complete interaction between student and teacher, including considerations of students' reactions to teacher actions (reciprocity).

The purpose of the current study is to explore caring relationships that may emerge in online settings and what technological choices facilitated a caring approach to teaching and learning. The research reported used interpretative phenomenological analysis (IPA) to answer these questions: What modes of communication do students and teachers use to communicate caring in the technology-mediated context of an open and online high school, what reasons do they have for using those modes, and how effective do they perceive these technologies to be at fostering caring? IPA is suitable for this study because it considers care through the examination of participants' experience rather than abstractions or theories (Reid, Flowers, \& Larkin, 2005).

\section{Methodology}

\section{Context}

This study was conducted in the Mountain Heights Academy (MHA) (formerly the Open High School of Utah) because it is an online high school in which teachers strive to maximize the time they employ working one-on-one with each student. Teachers disseminate content online and alternately use the time saved to attend to students' individual needs. MHA's data-driven learning management system enables one-on-one connections to develop based on up-to-date student performance. Another unique quality of this online setting is its aim to encourage collaboration between teachers, students, and parents. This emphasis on using data to guide choices about online interactions, and the focus on collaboration between teachers, students, and parents, is a unique aspect of the MHA setting, and emerged in the interviews as something the participants felt improved the caring relationship. The design and implementation of these qualities, among others, have helped MHA win several awards including a Gold Medal in the United States Distance Learning Association's Best Practices competition (2012) and the 2012 Best of State award for best charter school in Utah.

\section{Data Collection}

Participants consisted of two female teachers at MHA, two female students, and two male students. Both teachers were selected by the MHA administration as 
demonstrating a high level of caring. We chose this kind of purposive sampling in order to do a case study of how technologies could support caring pedagogies with teachers inclined towards this approach already. Each participating teacher created a list of five female and male MHA students from their class at large. They created these lists of students with whom they believed they shared their most quality caring relationships. All of the student participants were Caucasian, with ages ranging from 12 to 18.

We employed a three-stage semi-structured thematic interview series (Schuman, 1982) to allow participants to share in-depth accounts of their experience. The first interview inquired about the participant's background and prior experience in the online setting while also aiming to understand how teachers were involved in students' learning experiences in general. The second interview focused on understanding the caring experience and technology choices made to support caring interactions. The third interview followed up on any topics needing additional depth. Questions were openended and designed to encourage participants to share experiences openly.

\section{Analysis}

Interview transcripts were analyzed using the principles of interpretive phenomenological analysis (IPA, Smith, et al., 2009). Each transcript was thoroughly read and reviewed multiple times. The lead author first read the transcripts making no annotations and then a second time including annotations in the margins. After making initial annotations, the lead author coded each transcript, independent of other interviews, identifying new themes as they emerged. In coding, she was influenced by Nodding's caring pedagogy theory, although she maintained openness to other ideas that seemed relevant to the broad topic of technology-mediated caring in this setting. After reading over the list of emergent themes for all interviews, a table was created with clusters of themes organized into broader categories for each interview. After carefully examining the themes from each interview, connections across interviews were determined, and another table was created with a list of superordinate and subordinate themes across interviews with direct quotes. Each interview was then reviewed one last time to confirm that the experiences shared remained fairly accurate in the selection of quotes and interpretations of the data.

Field notes and a reflexive journal documented subjectivity checks and other research activities. Member checks were conducted before and after data analysis to preserve the accuracy of participant responses. Peer debriefings were useful in developing the interview protocol as well as in revising data collection and analysis methods. Triangulation between sources was sought to strengthen evidence of the themes. A negative case analysis indicated that the themes that emerged were an accurate reflection of the data collected (Lincoln \& Guba, 1985). 


\section{Findings}

This study describes how teachers and students at an online charter high school experienced and facilitated caring, primarily looking at how they fostered relationships and their technological preferences for doing so. We refer to the caring that occurs in the online context as technology-mediated caring (TMC).

\section{Knowing the Student}

In this study, teachers began caring interactions by first trying to understand students and their needs. Teacher participants explained that the process of "knowing" goes beyond just "being there." Teachers came to know students online through engaging in continuous dialogue, facilitating shared experiences, and maintaining vigilant observation to gain an understanding of the student's perspective.

\section{Continuous dialogue.}

At MHA, teachers engaged in dialogue to better know students and their needs. Technology facilitated dialogue by promoting teacher-student accessibility, enabling teachers to initiate dialogue, and facilitating promptness and clarity in communications. In addition, this theme revealed patterns related to teacher and student preferences. Teachers explained the importance of knowing and using the tools that students preferred in order to support the development of a caring relationship.

\section{Teacher-student accessibility.}

Both MHA teachers preferred technologies that increased teacher and student accessibility. Teacher 2 explained the daily process of letting her students know she was available and receptive. When she began work at her computer, she turned on all of her technology tools and set her status to "online" or "available," which she then communicated to the students in a class-wide email. Then, she began contacting students individually through Skype, Google Chat, email, or phone. During these interactions she remained attentive to Twitter and other tools that gave her information about students' status and needs.

Teacher 1 acknowledged the essential role of technology in providing students access to the teacher:

I couldn't even imagine going back to teaching in a bricks and mortar classroom without having all this technology to reach out to my students. The fact that they can get a hold of me 24/ 7 is amazing. (Teacher 1 )

In regards to student access, teachers mentioned that technologies that indicate student online access status (i.e., online, away, busy) -while not always accurate-were useful in facilitating dialogue. In general, participants indicated a preference for technologies 
such as Skype and Google Chat that provided them this access while displaying users' online status.

\section{Promptness.}

Participants also mentioned that caring involved prompt feedback and replies, something technology assisted with. Teacher 2 explained, "I do have kids that will text me quite a bit. . . . and . . . it takes me two seconds to text them back." One student said, "I can pull out my phone and . . . send them an email right there, and then normally I can expect within minutes to get another email back" (Student 2). Teachers and students also favored synchronous technologies such as chat and video that facilitated just-in-time help.

\section{Initiating dialogue.}

Teachers at MHA gained access to students by proactively initiating dialogue through automated messages. Although usually regarded as uncaring and impersonal, teachers used automated messages as opportunities to enter into dialogue with students, as well as an opportunity to balance their workload while ensuring a connection with each student individually. One teacher said:

That's been a lifesaver . . . that program has really made it easy to make sure those kids are contacted .... A lot of times they'll respond to me and they'll say, "hey, thanks for the email; I needed that encouragement." And then that starts up another conversation with them. I'll be, "okay, great. How are you doing? Can I help you with anything? It's another way of opening up that communication door." (Teacher 2)

MHA teachers personalized the messages by ensuring the student's name was on each email and accurately targeted the student's academic needs. Teacher 1 explained that automated messages aided teachers in caring for populations of students who may easily become forgotten online-including high achieving students.

\section{Shared experience.}

At MHA, teachers demonstrated receptivity to students by achieving a shared studentteacher perspective. Teachers made technology choices that allowed the teacher and student to work together, share a workspace, and reach a joint understanding of the problem. One teacher explained that the online context allowed her to provide prompt feedback that felt like teacher-student collaboration. She explained:

I bring it up and we work on it together within a Google doc, and so it's like instantaneous. And so I think the kids, because of instantaneous feedback, know that you care ... it can be more of a joint collaboration. (Teacher 2) 
The teachers valued the instantaneous delivery of technology messages because it allowed them to sustain shared synchronous teacher-student interactions that facilitated an in-depth understanding of student needs. Teacher 1 explained:

Sometimes we'll have Google Docs open and we'll be working on the same assignment, but we'll also be calling each other back and forth on Skype so we can talk and we can hear each other's voices.

As in these examples with Google Docs, for direct instruction, participants favored technologies that afforded a shared workspace. Teachers used screensharing tools to share a workspace with students and mutually work on solutions to academic tasks. Oneeko features that facilitated a shared experience included annotation and file transfer capabilities, a whiteboard, webcam integration, and multiple user access. Teachers also used Google tools because they offered the affordance of a shared workspace in addition to built-in features such as chat and video capabilities for communication. These tools provided a synchronous-like experience between teacher and student. The choice of technology varied according to student preferences and the nature of the task. Problems that were more urgent, such as those clarifying content during direct instruction, were better addressed through synchronous, while less urgent problems related to grading and assignment criteria were addressed through asynchronous technologies.

Students valued how technology helped achieve a shared experience with teachers. One student said:

I think it's pretty cool I can work on an assignment and send it to my teachers by email or I can put it in Moodle and download it as a pdf . . . and it will send me emails [if] they viewed it.. . . . It's also helpful when I can work on an assignment together with my teacher on Google docs. (Student 1)

For this student, technological affordances that indicated that the teacher had viewed or edited his project helped him feel cared-for. Such indicators fostered a sense of accountability in teachers and helped students perceive feedback as collaborative work.

\section{Vigilant observation.}

Teachers also learned about their students through observing students' online activity through various tools. Teacher 1 explained how important it is to observe each student's online activity to understand where to connect with students (Skype or Google Chat, for example). Teacher 2 explained that observing student status updates enabled her to detect when a student was struggling. She said: 
I think through online learning . . . it's easy to identify problems very easily. . . . J ust the other day in a Skype handle [status field], the kid wrote something to the effect that . . . today he was feeling blue . . . . I just Skyped him really fast and said, "hey, I just saw your [status]. Are you doing okay?" . . . And so he knew that somebody cared. (Teacher 2)

Both teachers agreed that technologies allowing students to communicate openly on a personal level provided a rich source of data to help them come to know students and their non-academic needs.

Other helpful technologies were found within the school's infrastructure. MHA is unique in the integration of Highrise, a customer relationship management tool that allows teachers to post updated notes on each student interaction. These notes are accessible to all teachers. Teacher 1 explained that she checked Highrise before interacting with students to read updated notes by other teachers about the student's needs. This allowed her to interact with the student based on updated information. Teachers explained that Highrise facilitated caring interactions by creating transparency between teachers regarding the interactions they have with students.

Teachers were also observant with regards to grades and performance patterns. The school's learning management systems, Moodle and Genius, were instrumental in providing teachers with updated grade reports. Teacher 2 explained:

Online you can ... know exactly which kids are failing . . .. It's like you can target them and ... it's like they've got an extra eye on them all the time. Whereas in a bricks and mortar school, they tend to slide through. . . . whereas here, they're easily identifiable. You can see them. (Teacher 2)

Teachers also used learning management systems to tag problems and schedule reminders to follow-up with students. This affordance was highly valuable because it helped maintain continual dialogue with students.

\section{Technology Preferences}

Teachers and students expressed distinct preferences in communication technologies for participating in caring interactions. Teachers utilized their knowledge of student technology preferences to support the teacher-student relationship and attend to students' needs. 


\section{Teacher technology preferences.}

Both teachers expressed that they came to know students best through video technologies. Teacher 1 said:

I do like the face-to-face on Skype . . . . The more they actually see me, the better, I think they relate to me. The video is really helpful in showing students that you care and that you know them.

The teachers believed video conferencing tools allowed them to be more observant and receptive of student verbal and non-verbal cues. Teacher 1 explained:

If you're talking to them and they say, "No. I don't have any questions" but their body language is telling you something totally different, then I can follow up and sort of get it out of them what they really need help with, and I find that it's a lot more effective to do those kinds of conversations over video conferencing.

Although teachers agreed in their preference of video technologies, they acknowledged that the majority of students preferred using chat and texting technologies.

I definitely have kids this year that they only want to chat, and I kind of wonder if I had started by calling them rather than sending them a message that that would have been the method of communication they would have gotten used to. (Teacher 1)

Teacher 1 also indicated that she preferred phone calls to emails and chat because it was more personable and synchronous. Teacher 2 listed Twitter as another tool of choice due to the visibility the Twitter feed affords to everyone in the school, reliability of the medium, and instantaneous speed. She recognized email as her least favorite medium due to its asynchronous nature. She also explained that students have a hard time initially connecting on the phone but agreed with Teacher 1 that they tend to warm up with time.

\section{Student technology preferences.}

All student participants indicated that the promptness and reliability supported by chat technologies was essential in helping them feel cared for. Students said they would rather use chat over video technologies due to speed and reliability issues. One student said about text chat technologies, "Even if you're working on an assignment, you can just quickly type in a question to one of your teachers and they'll instantly get back to you" (Student 4). In addition students preferred chatting because, as one student explained, "I can just type out something to them really fast . . . so I can still kind of work on my stuff while I'm waiting for them to type me back." Another student stated, 
"[Google chat] helps if they're also working with another student, I can just send a little chat so they can still communicate with the student and look at it when they're done." (Student 1)

Some students preferred chat because they did not feel comfortable connecting with teachers through non-text based tools such as phone or video conferencing. One teacher explained, "He's still really shy to talk to me. He doesn't even like talking on the phone, so ... I know he's definitely more comfortable with (Skype chat)" (Teacher 1). One student said:

I don't always like video chat, and I don't want people to see my face all the time. Depends on the day [laughter] . . . like if I'm just right out of bed then I don't like using the video. (Student 4)

Teachers agreed that most students found it difficult to use video technologies "until they get to know us and until we kind of create that bond," as Teacher 2 explained.

Teacher 1 added this was similar to how some students would probably feel about inperson communication:

He's just one of those kids that he will say what's on his mind on his computer that he would never really say to your face, I think. So, the fact that I could get him to open up to me and ask me questions about his essay assignment and what he needed to do and all of that and have an actual conversation with him over chatting-I don't think it would ever happen in a classroom face to face. (Teacher 1)

Overall, participants suggested that to achieve a caring interaction, the mediums mattered less than the content and quality of the interaction. For example, students recognized teachers' attributes, clarity of communication, accessibility, and affective attitudes as caring more often than the use of specific mediums of communication. Students highly valued text-based technologies with higher speeds of connectivity and accessibility, while teachers valued technologies that allowed them to connect with students at higher degrees of fidelity.

\section{Teacher technology choices that supported caring.}

According to teachers, using tools that students preferred ensured better dialogue. Teacher 2 explained, "On (Skype) even if I get a smart aleck answer sometimes at least he's reciprocating to me." For this teacher, getting the student to interact was more important than the specific technology used to mediate the interaction. Both teachers explained that they were willing to use any technology, even when it wasn't their preference, to support the development of a student relationship. When asked about 
the role of technology in caring for students, both teachers explained that one of their top priorities at MHA was to investigate what tools each individual student preferred. Teacher 1 explained, "I think that giving them the choice to use the technology that they feel comfortable with shows them that I care." Teacher 2 explained that she kept a spreadsheet documenting each student's individual communication technology preference.

Both teachers explained that, first, they established a relationship of trust in which the student felt confident and willing to open up to the teacher through technology. Then, they helped students progress to using more complex technologies with greater affordances. Teacher 1 shared an experience with a student who resisted connecting online. She explained that she began calling the student on the phone to create a relationship with the student by asking about her general interests. Once the student felt comfortable on the phone, the teacher suggested they begin using Skype. The teacher explained:

On one of the phone calls, I specifically said "well, next time why don't we just chat on Skype and see how it goes?" Because with all the screen sharing things we can do online, it's a lot easier to tutor a student on Skype or on Google Chat than it is over the telephone. So, I sort of pushed her in that direction.

This student explained that the teacher's actions helped her feel more confident in herself, the technology, and her ability to connect with the teacher and other students. While the teachers understood that it was their responsibility to help students gain confidence in the use of technology through first establishing a caring relationship, they indicated that in coercing a student to use a technology the student was not comfortable with, they ran the risk of harming the relationship. Thus teachers believed their priority was in maintaining the caring relationship.

The role of technology in online learning was essential in continuously providing teachers with prompt and accurate information about students' perspectives and circumstances. By getting to know students through shared experience, observation, and dialogue, teacher participants were prepared to execute caring actions to adequately meet student needs. Technology tools and features played a role in promoting continuous dialogue, facilitating a shared teacher-student experience, and enabling vigilant teacher observation. Based on this study, Table 1 provides some consideration in selecting tools to enable teachers to gain deep knowledge of their students. 
Table 1

Technology Choices for Understanding and Knowing the Student

\begin{tabular}{lll}
\hline Elements of caring & Considerations regarding tools \\
\hline Knowing the & - Get to know students/ & How well does this tool facilitate \\
student & students get to know & - dialogue? \\
teacher through & - teachers coming to know students' \\
- Continuous dialogue & Achieve shared teacher- & personal/academic interests? \\
student experience & - students communicating their \\
- Observe student online & feelings and ideas openly? \\
- activity & - a shared experience? \\
performance and & - a shared workspace? \\
interaction patterns & - teachers seeing the project from the \\
& students' perspective? \\
& - teachers observing student \\
& interactions and performance \\
& patterns? \\
& - teachers knowing students on a \\
& personal non-academic level? \\
& - teachers demonstrating to students \\
& that they see them as individuals \\
& with personal needs? \\
& - teachers helping students feel \\
& comfortable? \\
\hline
\end{tabular}

\section{Discussion}

This paper describes three themes related to understanding and coming to know a student-continuous dialogue, shared experience, vigilant observation. Perhaps the most salient theme, continuous dialogue, provided a way for teachers to come to a deep knowledge of each student. This theme is congruent with empirical research that has established dialogue as a critical element of the online learning process (Rovai, 2007; Stein, et al., 2005; Vrasidas \& McIsaac, 1999). Teacher and student participants preferred technologies that increased teacher-student accessibility by displaying users' online statuses. Synchronous and mobile technologies that were more instantaneous, such as chat, video conferencing, texting, and mobile phone emails, were mostly favored over asynchronous technologies. Teachers used an automated message system to create opportunities to initiate dialogue with each student individually.

This theme is closely related to literature that has established affective responses (i.e., expression of emotions, use of humor, self-disclosure) among online users as an element constituting social presence (Ledbetter, Mazer, DeGroot, Meyer, Mao, \& Swafford, 2011). In particular, self-disclosure has been recognized as an important element increasing social presence and supporting the construction of knowledge (Shamp, 1991) and improving student motivation and class climate (Mazer, Murphy, \& Simonds, 2009). The present study suggests that continuous dialogue is critical in 
achieving self-disclosure. The continuous quality inherent in caring dialogue makes synchronous technologies most suitable for technology-mediated caring (TMC). However, continuous caring dialogue may also be achieved with asynchronous technologies when teachers make an effort to provide prompt and responsive replies. In regards to dialogue, students favored affordances that enabled promptness and mobility over affordances that communicated non-verbal cues (i.e., video).

Students felt understood and cared-for when they perceived that teachers jointly experienced the learning process with them by working together with the student towards a specific project. This concept is similar to Noddings' (1984) concept of "duality" in which the teacher and student "see" and "feel" together (p. 30). Although students usually preferred synchronous technologies that enabled workspace sharing and instantaneous feedback, asynchronous technologies such as email were also effective in communicating care when they indicated to students that the teacher had paid significant attention to their specific project or need. This theme suggests that along with knowing the student, knowing the students' projects and experiencing it from the students' perspectives is critical in communicating care online. This finding agrees with literature related to teacher presence that rejects the idea of the teacher as "the guide on the side" indicating that teaching is most effective with "the active participation of a subject matter expert in the critical discourse" (Anderson, et al., 2001, p. 9). We propose that this may be done most effectively through technologies (i.e., Google Docs, Oneeko) that enable a shared teacher-student experience.

Another way teachers came to know students was through observation. Observing students' online activity gave teachers relevant knowledge about where to communicate with each individual student as well as knowledge related to their personal lives. Technologies such as Skype or Twitter that enabled students to openly communicate emotional or personal aspects of their lives were helpful. Technologies found within the schools' learning management system and customer relationship management tool allowed teachers to observe patterns of interactions students had with other teachers. We found that observations of student online activity and interactions provide a wealth of knowledge that is useful in attending to students' personal and academic needs.

This study provides evidence that caring begins with achieving a deep understanding and knowledge of the one cared for. These findings are congruent with Noddings' theory of care, which states that caring begins with engrossment, or receptivity to the cared-for. To achieve receptivity, a teacher must feel what the student feels, and see what the student sees. Thus, engrossment requires presence, but also an attempt by the teacher to come to know the student (Noddings, 1984). To "know" the student means to have knowledge of the students' realities in terms of their academic and personal lives, and to understand the project or task from their point of view (Noddings, 1984). This study suggests that in technology-mediated contexts, this also involves knowing the students' positions in regards to their knowledge and preference of technological tools. 
Students indicated a preference for chat technologies because they (1) enabled students to communicate with multiple people and work on academic tasks simultaneously, (2) were more reliable than video technologies, and (3) provided a safe distance for students with less self-confidence or desire to connect. However, teacher caring also involved helping students transition to technologies with greater affordances, while taking care not to damage the relationship. This transition enabled teachers to more effectively connect with students during direct instruction.

While some researchers have agreed that asynchronous technologies are less capable than synchronous technologies for facilitating immediacy (Rice, 1992; Short, Williams, \& Christie, 1976), others believe it is not the medium's affordances but the perceptions of the interactions that take place within the mediums that determine the perceived immediacy (Gunawardena \& Zittle, 1997; Richardson \& Swan, 2001; Walther, 1996). This study suggests that although synchronous affordances were considered helpful in facilitating caring interactions, it is the attentive intentions behind teacher actions that help students perceive caring.

\section{Limitations and Future Research}

This study primarily examined teachers' experiences with caring online. Further research examining male teacher perspectives in the online setting may be useful in identifying gender differences related to technology-mediated caring (TMC). A small sample size and the lack of observation data may also be limitations of this study. Finally, we purposively sampled teachers that were best cases, or in other words, those who were perceived to have caring dispositions. These methodological choices were made to allow us to see how caring can occur and how it emerges in student and teacher relationships under favorable circumstances.

Future research could build off of this study to examine whether these findings are applicable across larger and more diverse populations. In addition, researchers could study the degree to which establishing a caring relationship in the face-to-face context, prior to entering the online medium, may affect students' willingness to connect with teachers online using technologies with increased affordances (i.e., video technologies). In general, the introduction of the ethic of care theory to the technology-mediated context generates the need for research that acknowledges the role of teacher observations, teacher intentions and rationales for actions that increase presence and immediacy, and student reactions to TMC. Beyond considering specific teacher actions and behaviors, these concepts account for the broader context of relationship. Ultimately, it may be student perceptions of teacher caring that serve to decrease the psychological distance between teacher and student. 


\section{Conclusion}

In this study we examined teachers from an online charter high school, known for their caring dispositions towards students, to see how the technologies they used to mediate their interactions facilitate a caring approach to teaching. The findings suggest that arriving at a knowledge of the student through technology is possible and necessary for communicating caring to students. While a variety of technologies may be used to achieve technology-mediated caring, the content of the interactions and the attentiveness communicated to students may be of greater importance. These findings lead us to consider the importance of using a caring approach to pedagogy (Noddings, 1984) and the quality of the relationships in online learning beyond simply counting the number of interactions that occur or the level of social presence that is perceived. 


\section{References}

Andersen, J. (1979). Teacher immediacy as a predictor of teaching effectiveness. In D. Nimmo (Ed.), Communication yearbook 3 (pp. 543-559). New Brunswick, NJ : Transaction Books.

Anderson, T., Rourke, L., Archer, W., \& Garrison, R. (2001). Assessing teaching presence in computer conferencing transcripts. J ournal of the Asynchronous Learning Network, 5(2), 1-17.

Arbaugh, J . B. (2001). How instructor immediacy behaviors affect student satisfaction and learning in web-based courses. Business Communication Quarterly, 64(4), $42-54$.

Baker, J . A., Terry, T., Bridger, R., \& Winsor, A. (1997). Schools as caring communities: A relational approach to school reform. The School Psychology Review, 26(4), 586-602.

Baker, J . D. (2004). An investigation of relationships among instructor immediacy and affective and cognitive learning in the online classroom. The Internet and Higher Education, 7(1), 1-13.

Banks, R. (2009). Caring teachers and their impact: A phenomenological study of students' perceptions (Doctoral dissertation). Retrieved from ProQuest. (Publication No. 3382072)

Bangert, A. (2008). The influence of social presence and teaching presence on the quality of online critical inquiry. J ournal of Computing in Higher Education, 20(1), 34- 61.

Bulmer, M., \& Rodd, M. (2005). Technology for nurture in large undergraduate statistics classes. International J ournal of Mathematical Education in Science \& Technology, 36(7), 779- 787.

Damarin, S. K. (1994). Equity, caring, and beyond: Can feminist ethics inform educational technology? Educational Technology, 32(2), 34-39.

Delacruz, E. M. (2009). From bricks and mortar to the public sphere in cyberspace: Creating a culture of caring on the digital global commons. International J ournal of Education \& the Arts, 10(5). Retrieved from http:// www.ijea.org/v10n5/

Feldlaufer, H., Midgley, C., \&Eccles, J . (1988). Student, teacher, and observer perceptions of the classroom environment before and after the transition to junior high school. J ournal of Early Adolescence, 8(2), 133-156. 
Ferreira, M. M., Smith, G. R., \& Bosworth, K. (2002). Critical dimensions of the caring culture of an urban middle school. International Electronic J ournal for Leadership in Learning, 6(3). Retrieved from http:// www.ucalgary.ca/iejll/ferreira_smith_bosworth

Frymier, A. B., \& Thompson, C. A. (1992). Perceived teacher affinity-seeking in relation to perceived teacher credibility. Communication Education, 41(4), 388- 399.

Garrison, D. R., Anderson, T., \&Archer, W. (2000). Critical inquiry in a text-based environment: Computer conferencing in higher education. Internet and Higher Education, 2(2-3), 87-105.

Gleaves, A. \&Walker, C. (2006). How does digital caring differ from physical caring?: Examining students' experiences of and responses to a technological intervention within a caring pedagogy. In J . Fanghanel \&D. Warren (Eds.), Proceedings of the International Conference on the Scholarship of Teaching and Learning (2005 and 2006) (pp. 250-259). London, England: Centre for Educational and Academic Practices.

Goldstein, L. S. (1998). More than gentle smiles and warm hugs: Applying the ethic of care to early childhood education. J ournal of Research in Childhood Education, 12(2), 244- 261.

Goldstein, L. S. (2002). Commitment, community, and passion: Dimensions of a carecentered approach to teacher education. Teacher Education and Practice, 15(1/2), 36-56.

Goldstein, L. S., \& Freedman, D. (2003). Challenges enacting caring teacher education. J ournal of Teacher Education, 54(5), 441- 454.

doi:10.1177/0022487103259114

Goodenow, C. (1993). Classroom belonging among early adolescent students: Relationships to motivation and achievement. J ournal of Early Adolescence, 13(1), 21-43.

Goodlad, J . I. (1984). A place called school: Prospects for the future. MoGraw-Hill Companies.

Goodlad, J . I. (1990). Teachers for our nation's schools (1st ed.). San Francisco: J osseyBass.

Goodlad, J . I., Soder, R., \& Sirotnik, K. A. (1990). The moral dimensions of teaching. San Francisco: J ossey-Bass. 
Gunawardena, C., \&Zittle, F. (1997). Social presence as a predictor of satisfaction within a computer mediated conferencing environment. American J ournal of Distance Education, 11(3), 8- 26.

Hasenauer, S., \& Herrmann, M. (1996). Improving student behavior (Masters action research). Retrieved from ERIC. (Document Reproduction Service No. ED 408079)

Hirsch, B., \& Rapkin, B. (1987). The transition to junior high school: A longitudinal study of self-esteem, psychological symptomatology, school life, and social support. Child Development, 58(5), 1235-1243.

Holmberg, B. (2007). A theory of teaching-learning conversations. In M. G. Moore (Ed.), Handbook of distance education (pp. 69-74). Mahwah, NJ : Lawrence Erlbaum.

Ledbetter, A. M., Mazer, J . P., DeGroot, J . M., Meyer, K. R., Mao, Y., \& Swafford, B. (2011). Attitudes toward online social connection and self-disclosure as predictors of Facebook communication and relational closeness. Communication Research, 38(1), 27-53.

Lewis, J .L., Ream, R.K., Bocian, K.M., Cardullo, R.A., Hammond, K.A., \& Fast, L.A. (in press). Forthcoming: Con cariño: Teacher caring, math self-efficacy and math achievement among Hispanic English learners. Teachers College Record, 114(7).

Lincoln, Y. S., \& Guba, E. G. (1985). Naturalistic inquiry. Beverly Hills: Sage.

Lindmark, T., Marshall, J ., Riley, S., \& Strey, E. (1996). Improving behavior and academic success through a caring classroom. (Master's action research project). Retrieved from ERIC. (Document Reproduction Service No. ED 399493)

Mazer, J . P., Murphy, R. E., \& Simonds, C. J . (2009). The effects of teacher self-disclosure via Facebook on teacher credibility. Learning, Media and Technology, 34(2), 175-183.

McAlister, G. (2001). Computer-mediated immediacy: A new construct in teacherstudent communication for computer-mediated distance education. (Doctoral dissertation). Retrieved from ProQuest. (Publication No. AAT 3024479)

McArthur, R. C. (2005). Faculty-based advising: An important factor in community college retention. Community College Review, 32(4), 1- 19.

Mehrabian, A. (1971). Silent messages. Belmont, CA: Wadsworth. 
Moore, M. G. (1973). Toward a theory of independent learning and teaching. J ournal of Higher Education, 44(12), 661-679.

Moore, M. G. (1989). Editorial: Three types of interaction. American J ournal of Distance Education, 3(2), 1- 7.

Moore, M. G. (1993). Theory of transactional distance. In D. Keegan (Ed.), Theoretical principles of distance education (pp. 22-38). New York: Routledge.

Moore, M. G., \& Kearsley, G. (1996). Distance education: A systems view. Belmont, CA: Wadsworth.

Noddings, N. (1984). Caring: A feminine approach to ethics and moral education. Berkeley: University of California Press.

O’Sullivan, P. B., Hunt, S. K., \&Lippert, L. R. (2004). Mediated immediacy: A language of affiliation in a technological age. J ournal of Language and Social Psychology, 23(4), 464-490.

Pelowski, S., Frissell, L., Cabral, K., \&Yu, T. (2005). So far but yet so close: Student chat room immediacy, learning, and performance in an online course. J ournal of Interactive Learning Research, 16(4), 395-407.

Picciano, A. (2002). Beyond student perceptions: Issues of interaction, presence, and performance in an online course. J ournal of Asynchronous Learning Networks 6(1), 21- 40.

Picciano, A. G., \& Seaman J . (2007). K-12 onlinelearning: A survey of U.S. school district administrators. Retrieved from Sloan-C: http://sloanconsortium.org/sites/default/files/K-12_Online_Learning_1.pdf

Pomeroy, E. (1999). The teacher-student relationship in secondary school: Insights from excluded students. British J ournal of Sociology of Education, 20(4), 465-482.

Reid, K., Flowers, P., \&Larkin, M. (2005). Exploring lived experience. Psychologist, 18(1), 20-23.

Rice, R. E. (1992). Contexts of research in organizational computer-mediated communication. In M. LEA (Ed.), Contexts of computer-mediated communication (pp. 113- 144). New York: Harvester Wheatsheaf.

Richardson, J ., \& Swan, K. (2003). Examining social presence in online courses in relation to student's perceived learning and satisfaction. J ALN, 7(1), 68-88. 
Richardson, J . \& Swan, K. (2001). An examination of social presence in online learning: Students' perceived learning and satisfaction. Paper presented at the Annual Meeting of the American Educational Research Association, Seattle, WA.

Rovai, A. (2007). Facilitating online discussions effectively. The Internet and Higher Education, 10(1), 77- 88.

Schuman, D. (1982). Policy, analysis, education, and everyday life. Lexington, MA: Heath.

Schwier, R.A., \& Balbar, S. (2002). The interplay of content and community in synchronous and asynchronous communication: Virtual communication in a graduate seminar. Canadian J ournal of Learning and Technology, 28(2), 2130 .

Shamp, S. (1991). Mechanomorphism in perception of computer communication partners. Computers in Human Behavior, 7(3), 147-161.

Shann, M. H. (1999). Academics and a culture of caring: The relationship between school achievement and prosocial and antisocial behaviors in four urban middle schools. School Effectiveness and School Improvement, 10(4), 390- 413. doi:10.1076/ sesi.10.4.390.3490

Shea, P., Pickett, A.M., \& Pelz,W.E. (2003). A follow up investigation of teaching presence in the SUNY learning network. J ournal of Asynchronous Learning Networks, 7(2), 68-80.

Shea, P., Vickers, J ., \& Hayes, S. (2010). Online instructional effort measured through the lens of teaching presence in the community of inquiry framework: A reexamination of measures and approach. International Review of Research in Open and Distance Learning, 11(3), 127-154.

Short, J ., Williams, E., \& Christie, B. (1976). The social psychology of telecommunications. Toronto: Wiley.

Smith, J . A., Flowers, P., \& Larkin, M. (2009). Interpretative phenomenological analysis. London: SAGE Publications Ltd.

Teven, J . J . (2007). Teacher caring and classroom behavior: Relationships with student affect and perceptions of teacher competence and trustworthiness. Communication Quarterly, 55(4), 433-450. doi: 10.1080/01463370701658077

Tosolt, B. (2010). Gender and race differences in middle school students' perceptions of caring teacher behaviors. Multicultural Perspectives, 12(3), 145-151. 
Valenzuela, A. (1999). Subtractive schooling: US-Mexican youth and the politics of caring. Albany, NY: State University of New York.

Vrasidas, C., \& McIsaac, M. S. (1999). Factors influencing interaction in an online course. American J ournal of Distance Education, 13(3), 22- 36. doi:10.1080/08923649909527033

Wallace, G. (1996). Relating to teachers. In J . Ruddick, R. Chaplain, \& G. Wallace (Eds.), School improvement: What can pupils tells us? (pp. 29-40). London: David Fulton.

Walther, J . B. (1996). Computer-mediated communication: Impersonal, interpersonal, and hyperpersonal interaction. Communication Research, 23(1), 3-43. doi:10.1177/009365096023001001

Wentzel, K. R. (1997). Student motivation in middle school: The role of perceived pedagogical caring. J ournal of Educational Psychology, 89(3), 411-419. doi:10.1037/0022-0663.89.3.411

Wilson, J . H. (2006). Predicting student attitudes and grades from perceptions of instructors' attitudes. Teaching of Psychology, 33(2), 91-95.

\section{Athabasca University $\mathbf{Z}$}

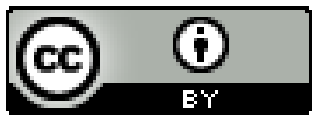

